\title{
Application of biotechnology to improve livestock products
}

\author{
Swati Gupta, C. V. Savalia \\ College of Veterinary Science $\&$ A.H., \\ Navsari Agricultural University, Navsari-396 450 (Gujarat) \\ Corresponding author: Swati Gupta, email: gswati24@gmail.com \\ Received: 27-02-2012, Accepted: 31-03-2012, Published Online: 28-07-2012 \\ doi: $10.5455 /$ vetworld.2012.634-638
}

\begin{abstract}
Biotechnological achievements of recent years have emerged as powerful tool to improve quality attributes of livestock products including milk and meat products. Biotechnological approaches can be employed for improving productivity, economy, physicochemical and nutritional attributes of a wide range of livestock products. The target areas of biotechnological research in the field of livestock products can be envisaged as production of high yielding food animal, improvement in quality of their products, enhanced production of natural food grade preservatives, efficient byproduct utilization and so forth. Many of the biotechnological techniques can be explored in the area of quality assurance programmes, which would be of great help to produce livestock products of assured quality and public health safety.

Keywords: biotechnology, livestock products, quality assurance programmes, public health safety, quality
\end{abstract}

\section{To cite this article:}

Gupta S, Savaliya CV (2012) Application of biotechnology to improve livestock products, Vet World, 5(10): 634638, doi: 10.5455/vetworld.2012.634-638

\section{Introduction}

Biotechnology is one of the frontier areas of scientific development in the world today. Advances in the fields of biotechnology catered to a wide area of science viz, Agriculture, Animal Sciences, Environmental Science, Food Science, Medicine etc. in order to improve the overall living standards of the human beings. This sphere of science is increasingly becoming sustainable means of improving livestock production by influencing animal health, nutrition, reproduction, genetics and breeding [1]. The main impediment to the successful application of biotechnology relates to the cost of adoption and acceptability [2]. The application of in-genuine biological principles in manipulating living organisms or their derivatives to either improve or multiply a product is biotechnology in simple means. The term can broadly be defined as the technology by which one can produce useful products from raw materials with help of living organisms or other biological processes. Biotechnological achievements of recent years have emerged as powerful tool to improve various livestock products including milk and meat products. The biotechnological tools can be applied in production of high yielding animal, improvement in the quality attributes of animal origin products, production of hormones, functional and designer livestock products, enzymes, bio-preservation of livestock products, efficient byproduct utilization, quality control and meat authentication as outlined below:

\section{Production of good quality and high yielding animal}

Livestock production is expected to grow tremendously in line with the projected demand for animal products. Therefore, the methods of livestock production must be changed to allow for efficiency and improvement in productivity. Biotechnological research is important in order to respond to the pressure of producing more food from animals to cater food requirement of the ever-growing human population [2]. Transgenic animals such as mice, rats, rabbits, pigs, sheep, and cows have been developed with the help of biotechnology. Transgenesis is the technique that permits the manipulation of genes of one organism which can subsequently be introduced into genome of another organism of same or other species in such a way that the genes are not only expressed but also gets transmitted to its progeny [3] Transgenic animals thus produced will have enhanced 
growth rate and improved food quality. For example, transgenic cows are developed to produce milk containing specific human proteins that helps in the treatment of human emphysema. Cloned transgenic cattle produced increased amount of beta and kappa casein in milk fat and increased level of human lactoferrin [4]. So also, such cows have been known to produce more milk or milk with less lactose or cholesterol, pigs and cattle that have more meat on them, and sheep that yield more wool. Pigs with human IGF 1 had 30 per cent more loin mass, 10 per cent more carcass lean tissue and 20 per cent less total carcass fat [5] . Transgenic pigs carrying plant gene had increased amount of unsaturated fatty acids in their muscle to produce a meat called "Healthy Pork" [6].

\section{I mprovement in quality of livestock products}

Major genes for meat quality offer excellent opportunities for increasing level of meat quality and decreasing variability. Most scientists say that tenderness is 30 per cent and Pale Soft Exudate (PSE) condition in swine is 50 per cent genetically governed characters. Gene that affects tenderness of meat before slaughter are CLPG in sheep, myostatin in beef, RN in pork. Rate of rigor mortis is governed by RYRI in pork ;during storage - Calpain : Calpastatin ratio and Cathepsin [7]. Identification, isolation and modification of useful genes are some of the important aspects of biotechnology research and development . The quality of carcass can be improved by manipulating the lipoprotein receptor and leptin genes thereby the cholesterol and fat content of meat can be governed.

\section{Production of hormones}

There is a growing database supporting the use of pituitary derived somatotropin (ST) as an agent to improve growth and carcass composition. Pigs injected with pST had 35 per cent less fat and 8 per cent more protein. However, purification of ST from Pituitary gland is uneconomical as production of single dose requires collection and processing of 25100 Pituitary glands. More recently, the development of recombinant DNA technology has provided a mechanism for large scale production of somatotropin. The gene for ST protein is inserted in laboratory strain of $E$. coli which can be grown on a large scale and from which ST can be purified and concentrated. Bovine and ovine ST improves growth rate by 20 per cent and lean to fat ratio by 40 per cent in ruminants. While experimentation in growing pigs, significant improvement of 40 per cent in average daily gain and 30 per cent in feed conversion efficiency had been achieved by administration of pST. Furthermore 60 per cent reduction in carcass fat and 70 per cent increase in carcass protein had been attained. No significant difference between effectiveness of pST and rpST had been observed [8].

\section{Production of Enzymes}

Dairy industry requires large amount of rennet to produce cheese in bulk. Traditionally rennet is procured from calves. However due to global imbalance between production of cheese and calf slaughter and worldwide shortage of calf rennet, exploration of alternative source of rennet is required to be investigated. In certain countries like India, religious feeling has aggravated the need to rennet substitute.

Treatment of milk with galactosidase results in hydrolysis of lactose, there by making it digestible by lactose intolerant people. The enzyme galactosidase hydrolyses lactose into glucose and galactose. Since these enzymes are costly, biotechnology can help in its economic production as well application [9]. Commercial -galactosidase is produced from yeasts such as Kluyveromyces lactis and Kluyveromyces marxianus (formerly known as Kluyveromyces fragilis and Saccharomyces fragilis), and moulds such as Aspergillus niger and Aspergillus oryzae. The production and optimization of -galactosidase enzyme using synthetic medium by Kluyveromyces lactis NRRL Y-8279 in shake flask cultures was found suitable [10]. Pure chymosin produced from genetically engineered $E$. coli reduced coagulation time by 5 folds. Cheese prepared with use of bacterial chymosin and ripened at $6-7 \mathrm{C}$ for 7 months showed similar characteristics and proteolysis to cheese made with calf chymosin [11].

The DNA of calf chymosin has been successfully cloned into yeast (Kluveromyces lactis), bacteria (E. coli) and moulds (Aspergillus niger). These can be produced on large scale by fermentation methods and extracted by down stream processing. Technological performance of recombinant chymosin is excellent since the cheese produced using recombinant chymosin is essentially indistinguishable from traditional cheese [12].

\section{Functional and designer livestock products}

In order to improve the product, attempts can be made to develop strains of starter cultures capable of enhanced antichlolestermic attributes, enhanced anti- 
carcinogenic attributes, enhanced antagonistic influence on enteropathogenic microorganism.

The genetic stability of starter strains, bacteriophage infection, production of off flavour and insufficient development of acid during fermentation are costly problems to dairy industry. Hence there is a great deal of interest in the development of new and improved strains, using modern techniques of molecular biology viz. plasmid transfer, transduction, protoplast fusion and cloning [11]. Plasmid biology of lactic acid bacteria have opened new vistas for exploring possibilities for using recombinant DNA technology and genetic engineering to improve the nutritional or therapeutic value of these products [12]. A complete phage resistant strain can be achieved by incorporating plasmid which are inhibitory for phage absorption, penetration and DNA metabolism [13].

Genetically engineered strains can play a vital role in manufacture of tailor made high quality fermented livestock products. Cloning of genes from lactic acid bacteria could be carried out in food grade strains of $E$. coli for which vectors \& transformation systems are available.

A detailed restriction endonuclease map of the citrate plasmid from Streptococcus lactis sub $s p$ diacetylactis have been produced and various parts of molecules are cloned to define citrate permeate genes for production of diacetyl [14].

\section{Biopreservation}

Livestock products being highly prone to microbial contamination and they undergo microbial deterioration. The recent trend of consumers towards food without artificial preservatives has led processors to search for natural preservatives. The antimicrobial system possessed by lactic acid bacteria offer scope for the development of an effective natural preservation process for application in food either as purified chemical agents or as viable cultures [15].

Suppression of spoilage and food borne pathogens by lactic acid bacteria could be extremely beneficial to human health and dairy industry as these attributes can considerably improve the shelf life and safety of fermented foods [16]. Lactic acid bacteria can act antagonistically against a wide range of food borne pathogens and spoilage organisms like Salmonella [17], Staphylococcus, Clostridium, Listeria monocytogenes, Yersinia enterocolitica and Psuedomonas.

Incorporation of certain antimicrobial agents to livestock products viz bacteriocin, nisin, $\mathrm{H}_{2} \mathrm{O}_{2}$, diacetyl, microgard, reutrin and pimaricin has yielded highly promising results and the enhanced shelf life of products thus attained would be economically, nutritionally and therapeutically beneficial both to manufactures \& consumers. Biotechnological techniques can now be applied to develop strains of lactic acid bacteria capable of enhanced production of these natural food grade preservative and also to combine within a single strain the ability of produce a number of such bacteriocin to extend their antibacterial spectrum.

\section{Byproduct utilization}

A major concern in the food processing industry is the development of methods to convert inedible and waste materials into new value-added products. Environmental and economic concerns necessitate a reduction of food processing waste, better use of raw materials and by products to new value added products.

The cheese industry generates billions of pounds of whey that must be disposed off. Ultrafiltration has provided the cheese maker with a means of concentrating the protein component of whey into a value-added item with significant dollar value. A recently developed bioconversion system employing selected strains of yeast can convert these solids to ascorbic acid with a market value of about $\$ 10$ per kilogram. The yeast biomass could be dried and used as single-cell protein supplements in animal feed.

Enzymatic treatment of food processing waste streams can produce materials readily metabolized by genetically engineered micro-organisms to produce antibiotics, hormones or peptides of interest in the pharmaceutical or chemical industries.

\section{Quality control}

Ensuring an acceptable level of food quality and safety is absolutely necessary to provide adequate protection for consumers and to facilitate trade. There must be a strong network of efficient quality assurance programme to monitor the quality and safety of these foods before reaching to the consumers. This can be largely possible with the application of recent developments in biotechnological tools in quality assurance programmes. The use of modern biotechnology has proved to be rapid, sensitive and accurate methods for detection and analysis of bacterial contaminants and pathogens or their toxins. Some of the most powerful tools of biotechnology which have already made great strides include rDNA technology, Genetic engineering, PCR, Microarray etc. Random amplified polymorphic DNA (RAPD) or amplified 
fragment length polymorphism (AFLP) molecular marker systems can also be used for the comparison of genetic differences between species, subspecies and strains, depending on the reaction conditions used. The use of combination of these technologies and other genetic tests allow the characterisation and identification of organisms at the genus, species, subspecies and even strain levels, thereby making it possible to pinpoint sources of food contamination, to trace microorganisms throughout the food chain or to identify the causal agents of food borne illnesses. Microarrays are biosensors which consist of large numbers of parallel hybrid receptors (DNA, proteins, oligonucleotides). Microarrays are also referred to as biochip, DNA chip, DNA microarray or gene arrays and offer unprecedented opportunities and approaches to diagnostic and detection methods. They can be used for the detection of pathogens, pesticides and toxins and offer considerable potential for monitoring the quality and safety of raw materials. Biotechnology has led to the development of tests that can be completed in one fifth of the time required by conventional methods. Development of new innovative methods for rapid detection of emerging high risk food pathogens such as E. coli O157, Listeria monocytogenes, Salmonella and Yersinia enterocolitica in food of animal origin is extremely important in context of food safety.

\section{Meat authentication}

In food production, raw materials from farm animals are typically processed to meat and cheese products. Ef? cient assays to detect the origin of meat precisely and rapidly are always in demand. Identi? cation of the meat origin from processed meat products is a current matter of concern for a variety of economic, religious, and health reasons. The extensive development of nucleic acid based technologies over the past decade re?ect their importance in food analysis [18]. DNA analytical methods offer a promising alternative for reliable species differentiation even in heated food samples, since the thermostability of DNA is much higher than that of proteins. Most of the DNA-based methods used rely on the simplicity and the sensitivity of the polymerase chain reaction (PCR). Species differentiation is achieved either by amplification of characteristic DNA fragments with species-specific primers or in the consensus PCR approach, by use of universal primers followed by sequencing [19] or restriction fragment length polymorphism (RFLP) analysis $[20,21]$ for the species-specific identification of the resulting amplicons.

\section{Conclusion}

Biotechnology brings production and quality revolution together with wholesomeness and nutritive value of the food products. Biotechnology plays a vital role to improve the quality of livestock products along with ensuring their safety from consumer point of view. New horizons may be explored using biotechnology for preparing nutritive food products with longer shelf life, superior quality as well as more acceptability in consumer market.

\section{References}

1. Bonneau, M. and Laarveld, B. (1999). Biotechnology in animal nutrition, physiology and health. Livest. Prod. Sci. 59: 223-241.

2. Kahi A.K. and Rewe T.O. (2008). Biotechnology in livestock production: Overview of possibilities for Africa. African J. of Biotech 7: 4984-4991.

3. Srinivasa V. and Goswami S.L. (2007). Transgenic farm animals - A mobile Pharmaceutical industry. Indian Dairyman 59: 26-32.

4. Brophy, B., Smolenski, G., Wheeler, T., Wells, D., L'Huilier, P. and Liable, G. (2003). Cloned transgenic cattle produce milk with higher levels of b-casein and k-casein. Nature Biotech., 21: 157-162.

5. Pursel, V.G., Wall, R.J., Mitchell, A.D., Elsasser, T.H., Solomon, M.B., Coleman, M.E., Mayo, F. and Schwartz, R.J. (1999). Expression of insulin-like growth factor-I in skeletal muscle of transgenic pigs. In transgenic animals in agriculture (J.D. Murray, G.B. Anderson, A.M. Oberbauer and M.M. McGloughlin, eds). CABI Publishing, New York, 131-144.

6. Neimann H. (2004). Transgenic pigs expressing plant genes. Proceeding of Natural Academy of Sciences, USA, 202: 7211-7222.

7. Murthy T.R.K. (2004). Biotechnological approaches for enhancing meat quality. Indian Food Industry 23: 24-26.

8. Solomon M. B. (2001). Meat science and application. edited by Y.H. Hui, Marcel Dekker Inc. Newyork, 127-144.

9. Ramesh, K. and Yadav, J.S. (1990). Biotechnological applications in dairy processing. Indian Dairyman 42: 264-268.

10. Dagbagli S. and Goksungur Y. (2008). Optimization of b-galactosidase production using Kluyveromyces lactis NRRL Y-8279 by response surface methodology. Electronic J. of Biotech 11: 3458.

11. Singhal, R.S., Sampat, S.K. and Gupta, R.K. (1990). Biotechnology in dairy industry. Indian Dairyman 42: 372-385.

12. Mathur, B.N., Rook, H. and Shthi, S. (2003). Recent trends in processing of genetically modified dairy foods. Indian Dairyman 55: 29-35.

13. Desai, N.B., Dave, R.J. and Thakur, P.N. (1992) 
Biotechnological approaches in dairy and food industry. Indian Food Industry, 11: 33-35.

14. Thompkinson, D.K. and Mathur, B.N. (1991). Current status of biotechnological application in dairy industry. Indian Dairyman 43: 9-11.

15. Sarkar, S. and Mishra, A.K. (2001). Biopreservation of milk and milk products. Indian Food Industry 20: 74-77.

16. Batish, V.K., Grover, S. and Neelakantan, S. (1993). Improving shelf life and safety of fermented milk products through genetically improved micro organism. Indian Dairyman, 45: 51-57.

17. El-Khatib T and El-Rahman HA (1987). A research note -Effect of garlic and Lactobacillus plantarum on growth of Salmonella typhimurium in Egyptian sausage and beef burger. J. of Food Protection 50: 310-314.
18. Gupta R., Rank D.N., Joshi C.G. (2011). Singlenucleotide primer extension assay of mtDNA to authenticate cattle and buffalo meat. Science Asia 37: 170-173.

19. Chen D., Bai F., Zhou M.L., Zhang X.Y., Wu D.J. (2008). Differentiation of Bos grunniens, Bos taurus, and Bubalus from meat products mixture based on mitochondrion 12S rRNA gene. Yichuan 30: 1008-1014.

20. Chen S.Y., Liu Y.P., Yao Y.G. (2010). Species authentication of commercial beef jerky based on PCR-RFLP analysis of the mitochondrial 12S rRNA gene. J. Genet Genomics 37: 763-769.

21. Wang Q., Zhang X, Zhang H.Y., Zhang J., Chen G.Q., Zhao D.H., Ma H.P., Liao W.J. (2010). Identification of 12 animal species meat by T-RFLP on the $12 \mathrm{~S}$ rRNAgene. Meat Sci. 85: 265-269. 